\title{
Implementation of a revised classification for intrapartum fetal heart rate monitoring and association to birth outcome: A national cohort study
}

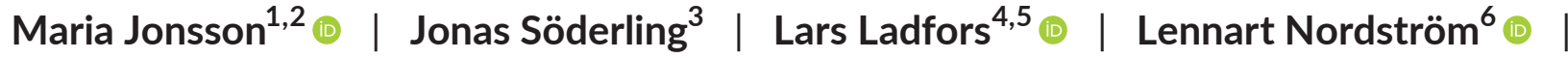 \\ Marianne Nilsson $^{5}$ | Michael Algovik ${ }^{7}$ | Mikael Norman ${ }^{8,9,10}$ | Malin Holzmann ${ }^{6,9}$ (c)
}

${ }^{1}$ Department of Women's and Children's Health, Uppsala University, Uppsala, Sweden

${ }^{2}$ Uppsala University Hospital, Uppsala, Sweden

${ }^{3}$ Department of Medicine, Solna, Karolinska Institutet, Stockholm, Sweden

${ }^{4}$ Institute of Clinical Sciences, Sahlgrenska Academy, Gothenburg University,

Gothenburg, Sweden

${ }^{5}$ Sahlgrenska University Hospital, Gothenburg, Sweden

${ }^{6}$ Department Women's and Children's Health, Karolinska Institutet, Stockholm, Sweden

${ }^{7}$ Västervik Hospital, Västervik, Sweden

${ }^{8}$ Department of Clinical Science, Intervention and Technology, Karolinska Institutet, Stockholm, Sweden

${ }^{9}$ Department of Neonatal Medicine, Karolinska University Hospital, Stockholm, Sweden

${ }^{10}$ Swedish Neonatal Quality Register, Stockholm, Sweden

\section{Correspondence}

Maria Jonsson, Department of Women's and Children's Health, Uppsala University, Akademiska sjukhuset, 75185 Uppsala, Sweden.

Email: maria.jonsson@kbh.uu.se

Funding information The Swedish Patient Insurance Company supported the ethical application, the acquisition of register data and statistical work. The funder had no role in the scientific work.

\begin{abstract}
Introduction: A revised intrapartum cardiotocography (CTG) classification was introduced in Sweden in 2017. The aims of the revision were to adapt to the international guideline published in 2015 and to adjust the classification of CTG patterns to current evidence regarding intrapartum fetal physiology. This study aimed to investigate adverse neonatal outcomes before and after implementation of the revised CTG classification.
\end{abstract}

Material and Methods: A before-and-after design was used. Cohort I $(n=160210)$ included births from June 1, 2014 through May 31, 2016 using the former CTG classification, and cohort II ( $n=166$ 558) included births from June 1, 2018 through May 31, 2020 with the revised classification. Data were collected from the Swedish Pregnancy and Neonatal Registers. The primary outcome was moderate to severe neonatal hypoxic ischemic encephalopathy (HIE 2-3). Secondary outcomes were birth acidemia (umbilical artery $\mathrm{pH}<7.05$ and base excess $<-12 \mathrm{mmol} / \mathrm{L}$ or $\mathrm{pH}<7.00$ ), A-criteria for neonatal hypothermia treatment, 5 -min Apgar scores $<4$ and $<7$, neonatal seizures, meconium aspiration, neonatal mortality and delivery mode. Logistic regression was used (period II vs period I), and results are presented as adjusted odds ratios (aORs) with $95 \%$ confidence intervals (95\% Cls).

Results: There were no statistically significant differences in HIE 2-3 (aOR 1.27; 95\% $\mathrm{Cl}$ 0.97-1.66), proportion of neonates meeting A-criteria for hypothermia treatment (aOR 0.96; 95\% Cl 0.89-1.04) or neonatal mortality (aOR 0.68; 95\% $\mathrm{Cl} 0.39-1.18$ ) between the cohorts. Birth acidemia (aOR 1.36; $95 \% \mathrm{Cl} 1.25-1.48)$ ) 5-min Apgar scores $<7$ (aOR 1.27; 95\% Cl 1.18-1.36) and $<4$ (aOR 1.40; 95\% Cl 1.17-1.66) occurred more often in cohort II. The absolute risk difference for HIE 2-3 was $0.02 \%(95 \% \mathrm{Cl} 0.00$ 0.04). Operative delivery (vacuum or cesarean) rates were lower in cohort II (aOR 0.82; $95 \% \mathrm{Cl} 0.80-0.85$ and aOR 0.94; 95\% $\mathrm{Cl} 0.91-0.97$, respectively).

Abbreviations: aOR, adjusted odds ratio; $\mathrm{Cl}$, confidence interval; CTG, cardiotocography; EFM, electronic fetal monitoring; HIE, hypoxic ischemic encephalopathy; OR, odds ratio; ua-pH, umbilical artery $\mathrm{pH}$.

This is an open access article under the terms of the Creative Commons Attribution-NonCommercial-NoDerivs License, which permits use and distribution in any medium, provided the original work is properly cited, the use is non-commercial and no modifications or adaptations are made.

(c) 2022 The Authors. Acta Obstetricia et Gynecologica Scandinavica published by John Wiley \& Sons Ltd on behalf of Nordic Federation of Societies of Obstetrics and Gynecology (NFOG) 
Conclusions: Although not statistically significant, a small increase in the incidence of HIE 2-3 after implementation of the revised CTG classification cannot be excluded. Operative deliveries were fewer but incidences of acidemia and low Apgar scores were higher in the latter cohort. This warrants further in-depth analyses before a full re-evaluation of the revised classification can be made.

\section{KEYWORDS}

cardiotocography, fetal acidemia, fetal heart rate monitoring, fetal hypoxia, fetal monitoring, fetal surveillance, guideline, hypoxic ischemic encephalopathy, obstetric labor

\section{1 | INTRODUCTION}

The aim of electronic fetal monitoring (EFM) during labor is to detect fetal hypoxia before adverse neonatal outcomes occur. Parameters assessed in the EFM tracing (ie, baseline, frequency, variability, accelerations and decelerations) are drawn from different scientific bases, ranging from detailed knowledge of origin via experimental animal studies (eg, umbilical cord compression and variable decelerations) ${ }^{1}$ to consensus based on retrospective observational studies (eg, normal interval of the baseline frequency). ${ }^{2}$

The strength of EFM is its high sensitivity with few false-negative results. One limitation is the low specificity with many false-positive results, which lead to interventions and associated risks for the woman without benefit for the infant. ${ }^{3}$ Sensitivity and specificity are dependent on the set limits for what is considered normal and pathological, respectively. The fewer EFM tracings considered normal, the higher the sensitivity of the classification but at the cost of a very low specificity. ${ }^{4}$ Sensitivity of EFM is also difficult to assess, given that the goal of intrapartum EFM is to prevent hypoxia-related injury rather than diagnose one that has already occurred.

National cardiotocography (CTG) classifications in different countries are often based on the international classification published by the International Federation of Gynecology and Obstetrics (FIGO) in 1987. ${ }^{5}$ Over the years, requirements for normality have gradually become stricter, and various national classifications differ in several aspects, ${ }^{6-9}$ including limits for normal baseline and definitions of decelerations and classification systems. In 2015, FIGO presented a new CTG classification. ${ }^{10}$ In response to the new international classification, the Swedish Society for Obstetricians and Gynecologists (SFOG) and the Swedish Midwife Association adapted the FIGO classification to the Swedish context.

The revised Swedish classification from $2017^{11}$ takes into greater account the inevitable normality of umbilical cord compression and pressure towards the fetal head during labor contractions than the former Swedish classification and the international FIGO classification from 2015 (eg, early and uncomplicated variable decelerations are considered normal intrapartum features in the revised classification, Table 1). This change might increase the challenge for midwives and obstetricians to understand the demarcation between harmless physiological fetal reactions and fetal responses that might be signs of hypoxia development.

\section{Key message}

A small increase in the incidence of hypoxic ischemic encephalopathy 2-3 after implementation of revised cardiotocography classification cannot be excluded. This finding, together with higher incidences of birth acidemia and low Apgar scores, are of concern and demand further analyses.

The study objective was to evaluate the introduction and implementation of the revised CTG classification in Sweden. The specific objective was to investigate whether there was a change in neonatal outcomes related to birth asphyxia and mode of delivery after compared with before the introduction of the revised Swedish CTG classification.

\section{2 | MATERIAL AND METHODS}

The working group that revised the CTG classification (MJ, LL, LN, $\mathrm{MNi}, \mathrm{MH}$ ) initiated the study. In addition, one neonatologist (MNo), one statistician (JS) and one member of the SFOG board (MA) were involved.

The revised classification was introduced nationwide during 2017. Data from the Swedish Pregnancy Register and the Swedish Neonatal Quality Register were used, and the population ( $n=338$ 329) consisted of singleton live-born infants from gestational week 34+0 or more from June 1, 2014 through May 31, 2016 (cohort I) and from June 1, 2018 through May 31, 2020 (cohort II). The following exclusions were made (International Classification of Diseases, Tenth Revision diagnostic codes): birth outside the hospital (Z38.1), breech lie (O64.1, O80.1, 083.1, O32.1), cesarean section before onset of labor (O82.0, O82.1), congenital malformations (Q00-Q99), fetal arrythmia (O36.8B) and fetal anemia (P61.4). After exclusions, 326768 births were included: 160210 in cohort I and 166558 in cohort II (Figure S1).

Data on maternal, pregnancy and delivery characteristics and perinatal outcomes were retrieved from the Swedish Pregnancy Register. Data prospectively entered in electronical medical 
TABLE 1 Differences between former and revised Swedish CTG classification systems

\begin{tabular}{|c|c|c|c|}
\hline & Baseline bpm & Variability bpm & Decelerations \\
\hline \multicolumn{4}{|c|}{ Normal CTG } \\
\hline Revised & $110-160$ & $5-25$ & $\begin{array}{l}\text { No repetitive or repetitive variable } \\
\text { uncomplicated/early }\end{array}$ \\
\hline Former & $110-150$ & $5-25$ or $\geq 2$ accelerations $/ 60 \mathrm{~min}$ & $\begin{array}{l}\text { None or early/variable uncomplicated with }<30 \mathrm{~s} \\
\text { duration and }<60 \mathrm{bpm} \text { depth }\end{array}$ \\
\hline \multicolumn{4}{|c|}{ Recommended action: No intervention } \\
\hline \multicolumn{4}{|c|}{ Suspicious CTG } \\
\hline Revised & $100-109$ or $>160$ & & $\begin{array}{l}\text { Repetitive variable complicated with normal } \\
\text { baseline and variability }\end{array}$ \\
\hline Former & $100-110$ or $150-170$ or $<100 \geq 3 \min$ & $\begin{array}{l}<5>40 \text { min, no accelerations or }>25 \\
\quad \text { or }<2 \text { accelerations } / 60 \text { min }\end{array}$ & $\begin{array}{l}\text { Variable uncomplicated } 30-60 \text { s duration and } \\
>60 \text { bpm depth }\end{array}$ \\
\hline \multicolumn{4}{|c|}{$\begin{array}{l}\text { Recommended action: Continuous CTG, correct reversible causes, consider fetal stimulation test/scalp blood sampling (in the former classification } \\
\text { if two or more suspicious criteria). }\end{array}$} \\
\hline \multicolumn{4}{|c|}{ Pathological CTG (former classification: $\geq 2$ suspicious criteria equaled pathological CTG) } \\
\hline Revised & $<100 \mathrm{bpm}$ & $\begin{array}{l}<2 \text { or } 2-5>60 \mathrm{~min} \\
>25>30 \mathrm{~min} \\
\text { Sinusoidal }>30 \mathrm{~min}\end{array}$ & $\begin{array}{l}\text { Repetitive late }>30 \mathrm{~min} \text {; if tachycardia/decreased } \\
\text { variability }>20 \mathrm{~min} \\
\text { Repetitive variable complicated in combination } \\
\text { with tachycardia/decreased variability } \\
>20 \mathrm{~min} \\
\text { Repetitive prolonged (>3 min), one prolonged } \\
\text { (>5 min) }\end{array}$ \\
\hline Former & $\begin{array}{l}>170 \\
<100 \geq 3 \min \end{array}$ & $\begin{array}{l}<5>60 \text { min with no accelerations } \\
\text { Sinusoidal }\end{array}$ & $\begin{array}{l}\text { Variable complicated }>60 \mathrm{~s} \text {, late decelerations, } \\
\text { combined decelerations }\end{array}$ \\
\hline \multicolumn{4}{|c|}{ Recommended action: Correct reversible factors, perform fetal stimulation test/scalp blood sampling or deliver the fetus } \\
\hline \multicolumn{4}{|c|}{ Preterminal CTG (only in former classification) } \\
\hline \multicolumn{4}{|c|}{ Former classification only: variability $<2 \mathrm{bpm}$ without accelerations regardless of decelerations and baseline. } \\
\hline \multicolumn{4}{|c|}{ Recommended action: immediate delivery } \\
\hline In the revis & assification, absent variability ( $<2$ spn & pathological and demands prompt as & ssment and measures \\
\hline
\end{tabular}

Abbreviations: bpm, beats per minute; CTG, cardiotocography.

records by midwives and physicians were forwarded to the register. This national register has been validated and covers $92 \%$ of all births in Sweden. ${ }^{12,13}$ The Swedish Neonatal Quality Register provided data on all newborn infants admitted for neonatal care. ${ }^{14}$ Data were prospectively collected using standardized forms, and the register has high validity. Data from the Swedish Pregnancy Register and the Swedish Neonatal Quality Register were linked using the unique personal identity number allocated to all Swedish citizens.

Cohort II was exposed to the revised CTG classification, and cohort I was reference. The revised Swedish and the FIGO classifications are presented in Figure S2. Both classifications consider variable decelerations to be uncomplicated if the duration is $<1 \mathrm{~min}$ and complicated if $\geq 1 \mathrm{~min}$. The frequency of contractions is not included as a variable in the revised classification but is commented upon, that is, contractions should not exceed five in $10 \mathrm{~min}$. In the former classification, more than five contractions in 10 min were classified as suspicious CTG.

CTG traces were classified as normal, suspicious or pathological. Differences between the revised and the former Swedish CTG classifications are described in Table 1. ST analysis might have been used to a limited extent in cohort I but in few instances.
The primary outcome was moderate to severe (grade 2-3) neonatal hypoxic ischemic encephalopathy $(\mathrm{HIE})$ as defined by Levene et al. ${ }^{15}$ and Sarnat and Sarnat. ${ }^{16}$

Secondary outcomes were vacuum extraction delivery, cesarean delivery, umbilical artery $\mathrm{pH}(\mathrm{Ua}-\mathrm{pH})<7.05$ and base excess $<$ $-12 \mathrm{mmol} / \mathrm{L}$ or $\mathrm{Ua}-\mathrm{pH}<7.00$, A-criteria for neonatal hypothermia treatment for HIE (any of 10-min-Apgar scores $<6$, ongoing neonatal resuscitation at $10 \mathrm{~min}$, artery/capillary $\mathrm{pH}<7.00$ during first $60 \mathrm{~min}$, base excess $<-16$ during first $60 \mathrm{~min}),{ }^{17}$ Apgar scores $<4$ or $<7$ at $5 \mathrm{~min}$, neonatal seizures, meconium aspiration and neonatal mortality.

\section{1 | Statistical analyses}

Characteristics of study subjects are presented as numbers and proportions, and continuous variables are presented as mean (SD), median (interquartile range), and range (min-max).

Logistic regression was used to estimate odds ratios (ORs) and 95\% confidence intervals (95\% Cls). Adjusted ORs (aORs) were estimated by including maternal age (continuous), level of education (<9/9/10-12/>12 years/missing), country of birth (Nordic/ 
non-Nordic/missing), living with partner (yes/no/missing), parity (0/1/ $\geq 2$ /missing), body mass index (BMI; $<18.5 / 18.5-<25 / 25-<$ $30 / 30-<35 / 35-<39 / \geq 40 /$ missing), smoking in early pregnancy (yes/no/missing) and gestational diabetes as covariates in the model.

We also present both unadjusted and adjusted risk differences. The adjusted risk difference (events per 100 births) was calculated as $(\mathrm{aOR}-1) \times$ the proportion in cohort I.

Data were analyzed using SAS software, version 9.4 (SAS Institute). Two-sided $p$ values of $<0.05$ were considered to indicate statistical significance.

\section{2 | Ethical approval}

Ethical approval was granted in November 2019 by the Swedish Ethics Review Authority (2019-05441 and 2020-03322).

\section{3 | RESULTS}

The first study period included 160210 live births (cohort I), and the second included 166558 live births (cohort II) (Figure S1). Table 2 shows that women were slightly older and had marginally higher BMI in cohort II than in cohort I. A larger proportion of women originated from non-European countries and had a history of cesarean section in cohort II than in cohort I. Gestational ages of the cohorts were harmonized, but fewer women in cohort II reached a gestational age of $\geq 42$ weeks. Oxytocin was used in $41 \%$ of labors in cohort II compared with $36.1 \%$ in cohort I. The proportion of infants born small for gestational age was comparable between groups. Newborns more often received neonatal care in cohort II.

Table 3 displays the primary and secondary outcomes in the cohorts with crude ORs and aORs. There was no statistically significant difference in frequencies of the primary outcome moderate to severe HIE between the cohorts: aOR 1.27 (95\% Cl 0.97-1.66). Nor was there any significant difference in frequencies of newborns with A-criteria for hypothermia treatment for HIE: aOR $0.96(95 \% \mathrm{Cl}$ 0.89-1.04). The aOR for neonatal mortality was lower in cohort II but not significant (aOR 0.68; 95\% Cl 0.39-1.18).

Larger proportions of newborns in cohort II than in cohort I had metabolic acidemia or Ua-pH $<7.00$ (1.19\% vs $0.84 \%$; aOR 1.36; $95 \%$ Cl 1.25-1.48), Apgar scores < 4 at 5 min (0.20\% vs 0.14\%; aOR 1.40; $95 \% \mathrm{Cl} 1.17-1.66)$ and $<7$ at $5 \mathrm{~min}$ (1.05\% vs 0.81\%; aOR 1.27; 95\% $\mathrm{Cl}$ 1.18-1.36). The proportion of newborns with neonatal seizures was also higher in cohort II than in cohort I $(0.19 \%$ vs $0.13 \%$; aOR 1.40; 95\% Cl 1.17-1.66).

The incidences of cesarean delivery (aOR $0.94 ; 95 \% \mathrm{Cl} 0.91-$ 0.97 ) and of operative vaginal delivery (aOR 0.82; 95\% Cl 0.80-0.85) were lower in cohort II than in cohort I. When adding oxytocin as a confounder, the OR for HIE grade 2-3 was attenuated (aOR 1.24; $95 \% \mathrm{Cl} 0.95-1.63$ ) as were the increased risks for birth acidemia and low Apgar scores (Table 3).
In general, the absolute risk differences between cohort I and II for neonatal secondary outcomes were small. They ranged from $0.05 \%$ for neonatal seizures and $0.05 \%$ for Apgar scores $<4$ at $5 \mathrm{~min}$ to $0.22 \%$ for Apgar scores $<7$ at $5 \mathrm{~min}$ and $0.30 \%$ for metabolic acidemia or Ua-pH $<7.00$ (Table 4).

\section{4 | DISCUSSION}

Frequencies of HIE grade 2-3 did not differ significantly after introduction of the revised Swedish CTG classification. Analyses of secondary outcomes showed that a larger proportion of infants born after the change in classification had low Apgar scores and were acidemic compared with those born before the change, but the risk differences were minor. Frequencies of operative deliveries were lower in the period after the change, which was expected since the revised classification normalizes some fetal heart rate (FHR) characteristics that formerly demanded intervention.

The study population was based on data from validated registers with excellent completeness. ${ }^{14,18,19}$ The large number of prospectively collected variables made it possible to control for several covariates. The large sample size enabled the use of rare outcomes such as HIE grade 2-3 and neonatal mortality.

The data reflect obstetric care of our population during usage of two different classification systems. This is in contrast to many studies designing constructed settings with selected populations and retrospective assessments of CTG traces by assessors blinded to all circumstantial information. ${ }^{4,20-27}$ Their intention to reduce bias also decreases external validity, whereas our findings reflect the everyday clinical obstetric care in Sweden.

One limitation is the retrospective design comparing two different time periods. The observational nature of the study can only show associations and not causal relations. Other circumstances and conditions in Swedish obstetric care and in the pregnant population might have changed during the total observation time of 6 years. As examples, our data showed that the use of oxytocin, a known risk factor for acidemia, was higher, and fewer women gave birth at or beyond 42 weeks, after than before the classification change. In spite of our efforts regarding exclusion criteria and control for confounding factors, residual confounding is a possibility.

Another limitation is that our study did not include analysis of actual CTG traces. No information on intrapartum FHR patterns is available in the national registers. The analyses of register data are at an aggregated level, so no detailed information on the individual laboring processes or decisions regarding expectant management or intervention is available.

Several potential biases need consideration. The Swedish Pregnancy Register has $92 \%$ coverage, ${ }^{12,13}$ and registered rates of admission CTG were equally high during both periods $(98.7 \%$ and $99.0 \%$, respectively [Table 2]), but we have no information on proportions of intermittent and continuous CTG during labor in the study populations. However, guidelines regarding indications for 
TABLE 2 Characteristics of the study population

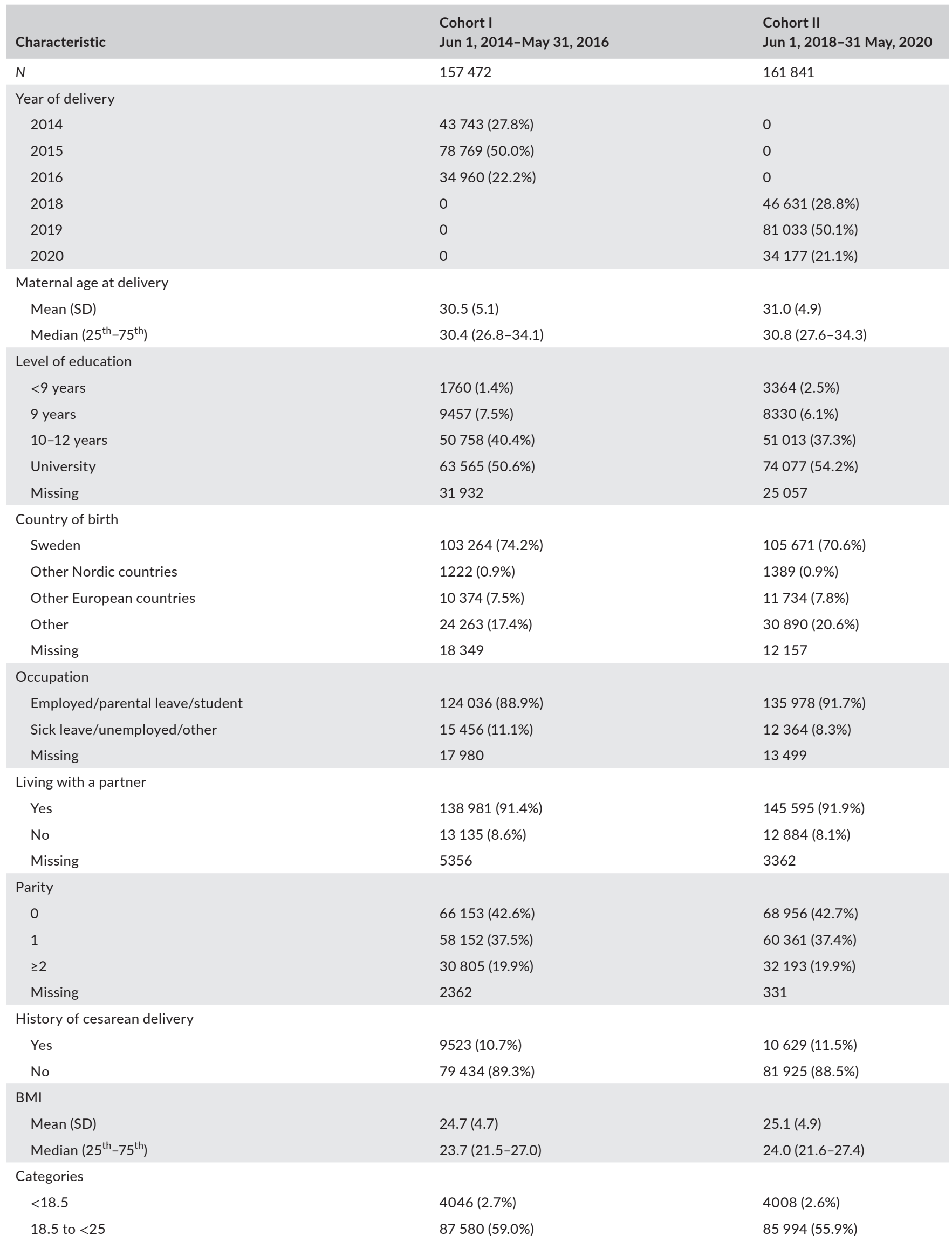


TABLE 2 (Continued)

\begin{tabular}{|c|c|c|}
\hline Characteristic & $\begin{array}{l}\text { Cohort I } \\
\text { Jun 1, 2014-May 31, } 2016\end{array}$ & $\begin{array}{l}\text { Cohort II } \\
\text { Jun 1, 2018-31 May, } 2020\end{array}$ \\
\hline 25 to $<30$ & $37623(25.4 \%)$ & $41132(26.8 \%)$ \\
\hline 35 to $<40$ & $4132(2.8 \%)$ & $5086(3.3 \%)$ \\
\hline$\geq 40$ & $1406(0.9 \%)$ & $1843(1.2 \%)$ \\
\hline \multicolumn{3}{|l|}{ In vitro fertilization } \\
\hline Yes & 4763 (3.3\%) & $6392(4.1 \%)$ \\
\hline No & 138388 (96.7\%) & $147753(95.9 \%)$ \\
\hline Missing & 14321 & 7696 \\
\hline \multicolumn{3}{|c|}{ Smoking in early pregnancy } \\
\hline Missing & 2939 & 4950 \\
\hline \multicolumn{3}{|l|}{ Diseases } \\
\hline Hypertension & $665(0.4 \%)$ & $658(0.4 \%)$ \\
\hline Diabetes (type I or II) & $782(0.5 \%)$ & 1099 (0.7\%) \\
\hline Gestational diabetes & $2522(1.6 \%)$ & $6518(4.0 \%)$ \\
\hline IBD & $1100(0.7 \%)$ & 1181 (0.7\%) \\
\hline Psychiatric disease & $16446(10.4 \%)$ & 26069 (16.1\%) \\
\hline \multicolumn{3}{|l|}{ Admission CTG } \\
\hline Normal & 123903 (93.1\%) & 131963 (95.5\%) \\
\hline Mean (SD) & $40.0(1.4)$ & $39.9(1.4)$ \\
\hline \multicolumn{3}{|l|}{ Categories } \\
\hline $34-36$ & $4884(3.1 \%)$ & 4819 (3.0\%) \\
\hline $37-39$ & $65446(41.6 \%)$ & 68951 (42.6\%) \\
\hline $40-41$ & $77182(49.0 \%)$ & 80404 (49.7\%) \\
\hline$\geq 42$ & $9960(6.3 \%)$ & 7667 (4.7\%) \\
\hline \multicolumn{3}{|l|}{ Small for gestational age } \\
\hline Yes & $2826(1.8 \%)$ & 2864 (1.8\%) \\
\hline No & 154545 (98.2\%) & $158658(98.2 \%)$ \\
\hline Missing & 101 & 319 \\
\hline \multicolumn{3}{|l|}{ Neonatal care } \\
\hline Yes & 8380 (5.3\%) & 9375 (5.8\%) \\
\hline
\end{tabular}

Abbreviations: BMI, body mass index; CTG, cardiotocography; IBD, inflammatory bowel disease; SD, standard deviation.

intrapartum FHR surveillance did not change between the study periods, and there were no indications of altered scoring of HIE in neonatal intensive care units during the study period.

We used neonatal HIE grade 2-3 as the primary outcome. While HIE grade 2-3 in asphyxiated neonates is related to functional disability in later life, this register study could not assess the associations between the revised CTG guidelines and long-term outcomes in the offspring. A national test program for neurological and cognitive function at 2 and 5.5 years was introduced in 2015 for severely asphyxiated babies, but it has only recently been reported to the 

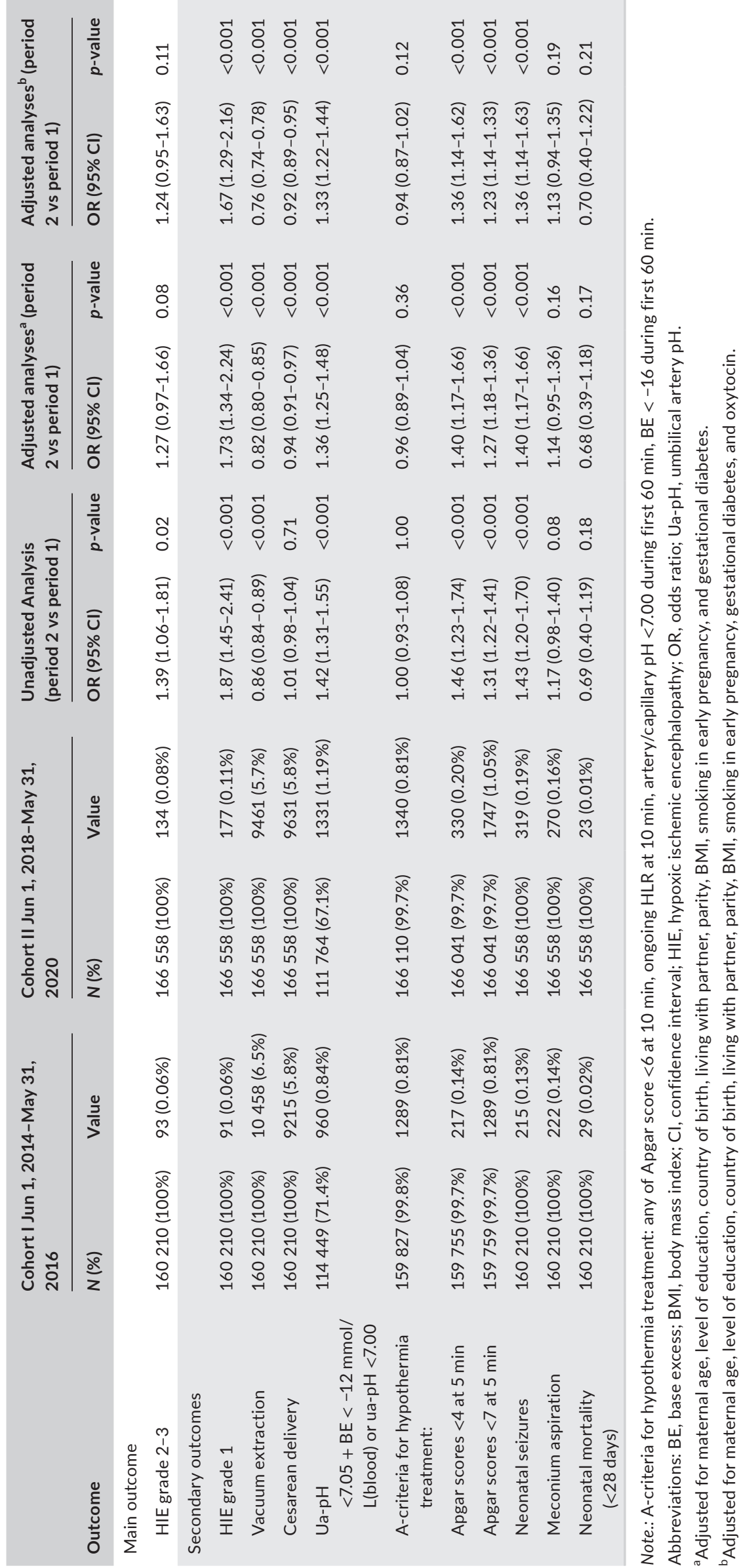


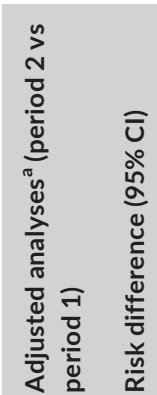

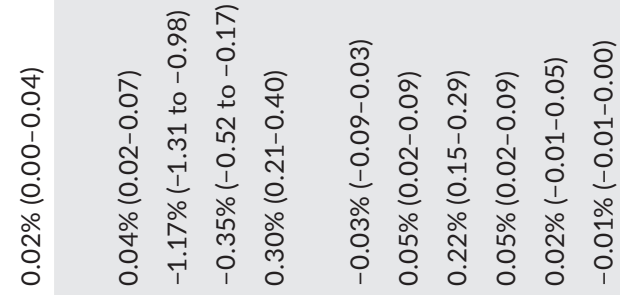

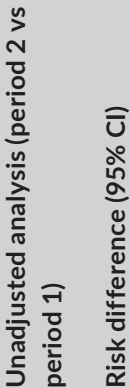

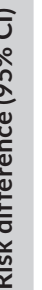

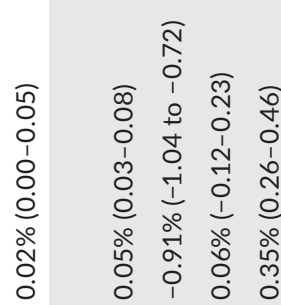

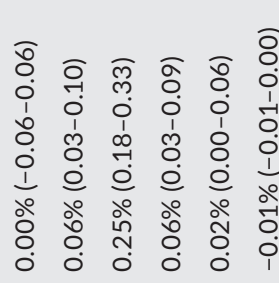

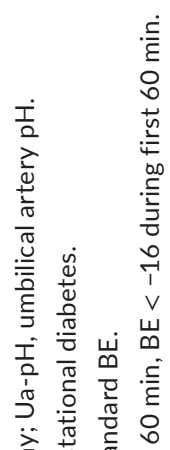

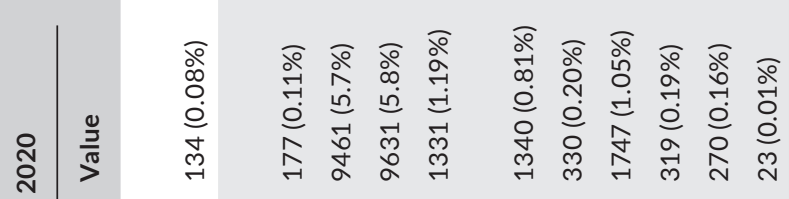

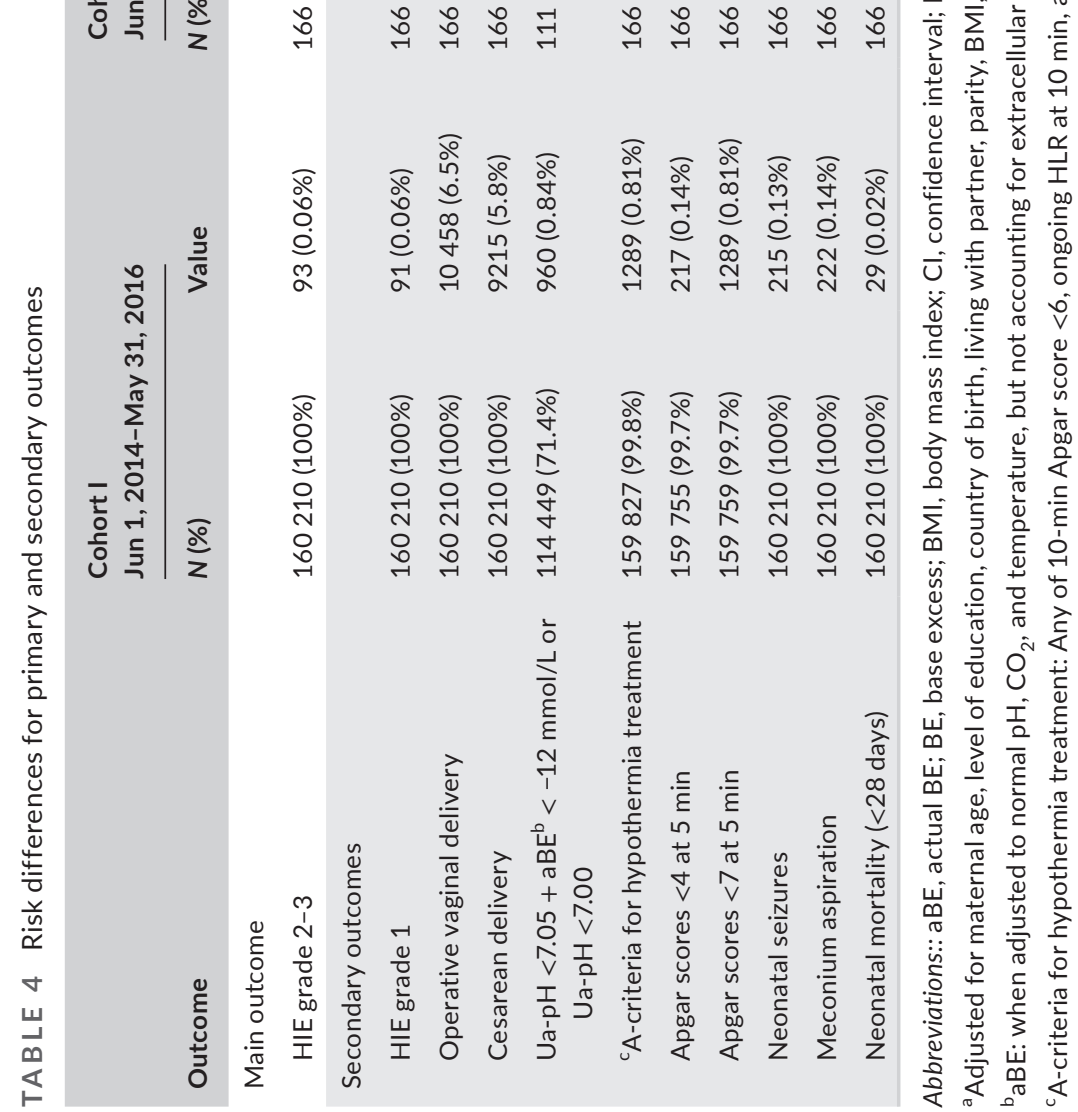

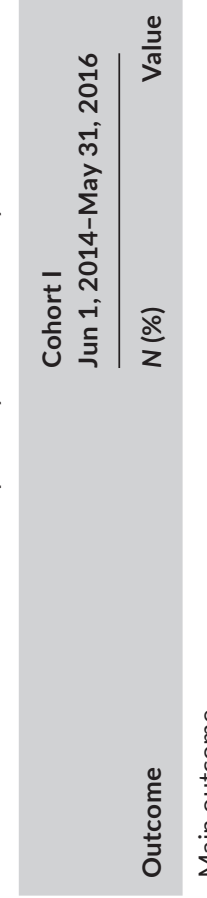

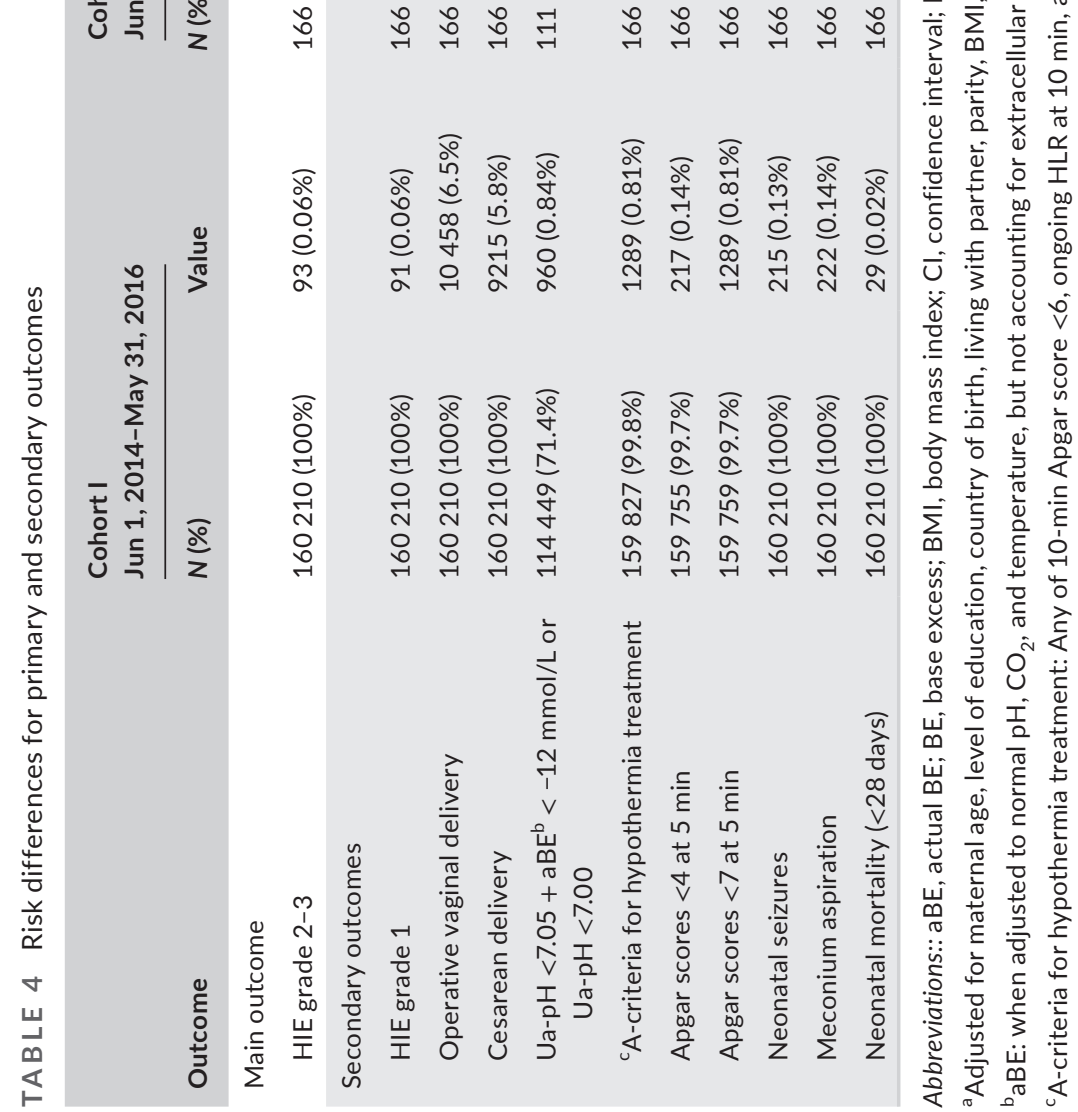

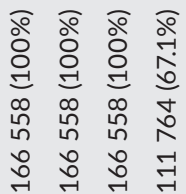

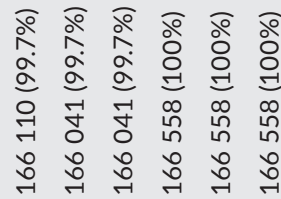

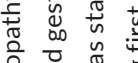

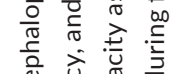

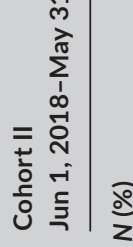

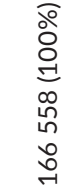

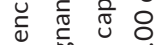

늘

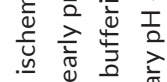

岸 $\stackrel{0}{=}$

(ํ)

岌它祀离 
Swedish Neonatal Quality Register, and data are restricted to infants undergoing neonatal hypothermia therapy.

There was no validation regarding adherence to the revised classification. Given the time it can take to change practice in clinical settings, it could be argued that the revised classification was not yet fully implemented in all units. However, all hospitals were contacted regarding their date for transition to the revised classification, and only those reporting transition well before the second study period were included. In addition, the national web-based CTG education (https://www.ctgutbildning.se) was updated in parallel with the introduction of the revised classification and is frequently used by midwives and doctors (about 8000 unique visitors per month, personal communication).

There was no significant difference in the incidence of HIE grade 2-3 between the time epochs, but we acknowledge the potential risk for type II error. The results might conceal a slight increase in risk for HIE grade 2-3 considering the lower limit of the $\mathrm{Cl}$, but the absolute risk differences are very low. In addition, the large study population of more than 300000 neonates argues against lack of statistical power.

The difference in oxytocin use between the cohorts means caution should be used when interpreting the results. The higher proportion of use in cohort II might reflect increased numbers of labor inductions, which would motivate adjusting for oxytocin. However, it might also be a consequence of more fetuses assessed as having normal FHR in cohort II, leading to more liberal use in labors with dystocia, in which case oxytocin would not be adjusted for. Therefore, we present aORs both with and without adjustment for oxytocin.

To our knowledge, this is the first study that compares different CTG classifications regarding neonatal outcomes using real-world data, reflecting everyday management. Several studies have tried to examine the sensitivity and specificity of different classification systems. ${ }^{4,20-27}$ Some focused on interobserver agreement, ${ }^{4,21-24}$ and some related to neonatal short-term outcomes using a proxy of Ua-pH with various cut-offs: 7.00, 7.05, 7.10, and 7.15.4,20,22-27 Several studies using $\mathrm{Ua}-\mathrm{pH}$ as an outcome have chosen cohorts with an exceptionally high frequency of acidemic newborns, ranging from the entire cohort, ${ }^{25}$ via case-control $1: 1,{ }^{20,23} 1: 2,{ }^{27}$ up to $1: 3{ }^{24,26}$ This might introduce various types of bias. Santo et al. had a more well-distributed cohort with $4.6 \%$ of newborns having Ua-pH $<7.05 ;^{22}$ however, their total sample size of 151 individuals resulted in a loss of precision and validity. Their study included seven infants with Ua-pH $<7.05$ and none with HIE. All studies hid background and circumstantial information from the assessors with the good intention of avoiding bias. However, an important argument regarding the use of EFM as a tool in obstetric care is that decisions and interventions are taken upon FHR changes in combination with the knowledge of all details surrounding the laboring woman, including clinical status at the time of FHR assessment (eg, obstetric history, known or suspected complications regarding woman or fetus, position and status of presenting part, estimated time to birth).
Several of the aforementioned studies presented the sensitivity and specificity properties of classification systems. The concept of defining a positive test as one that identifies neonatal morbidity is somewhat doubtful because all intrapartum fetal monitoring aims to prevent rather than predict negative outcomes for the neonate. Additionally, definitions of abnormality must not include a majority of the studied populations. Some classifications result in three out of four labors being assessed as suspicious or pathological, which leads to unnecessary interventions. ${ }^{27}$ As previously pointed out, ${ }^{26}$ the main difference between the revised and former Swedish classification as well as FIGO 2015 is the definition and classification of decelerations. Since variable decelerations are present in the vast majority of labors because of compression of the umbilical cord during contractions, one aim of the revised classification was to allow for physiological reactions to be classified as normal instead of suspicious. Such revision of the classification of CTG requires extended knowledge of fetal physiology among midwives and obstetricians. While the e-learning program on fetal surveillance (https:// www.ctgutbildning.se) was updated and courses for residents include teaching of the revised classification, there was no formal guidance on how to prepare all delivery unit personnel and educate them about the revised classification. The implementation was up to the individual departments.

\section{5 | CONCLUSION}

There was no statistically significant difference in frequencies of severe neonatal outcomes such as moderate to severe HIE or neonatal mortality after changing the Swedish CTG classification to a more liberal and normalizing categorization of FHR patterns. Although insignificant, a small increase in HIE grade 2-3 cannot be excluded. Operative deliveries were significantly lower after the introduction of the revised classification. Even though causality cannot be proven, the tendency for a higher frequency of HIE grade 2-3, acidemic newborns and low Apgar scores after introduction of the revised guidelines deserves continued attention. These findings may have several explanations that will need further exploration.

Therefore, the working group plans further studies with in-depth analyses of FHR patterns. Likewise, educational efforts and follow-up of compliance with the revised classification are also important.

\section{CONFLICT OF INTEREST}

MNo, MJ, LL and MA are medical advisors at the Swedish Patient Insurance Company.

\section{AUTHOR CONTRIBUTIONS}

All authors participated in the design of the study. Data collection and statistical analyses were performed by JS. All authors contributed to interpretation of the results. $\mathrm{MJ}$ and $\mathrm{MH}$ drafted the manuscript. All authors contributed to critical revision and gave approval of the final version to be submitted. 


\section{ORCID}

Maria Jonsson (iD https://orcid.org/0000-0002-2657-1958

Lars Ladfors (D) https://orcid.org/0000-0002-7512-2059

Lennart Nordström (D) https://orcid.org/0000-0002-7547-2569

Malin Holzmann (D) https://orcid.org/0000-0002-2640-0753

\section{REFERENCES}

1. Westgate JA, Wibbens B, Bennet L, Wassink G, Parer JT, Gunn AJ. The intrapartum deceleration in center stage: a physiologic approach to the interpretation of fetal heart rate changes in labor. Am J Obstet Gynecol. 2007;197(236):e1-e11.

2. Pildner von Steinburg S, Boulesteix A-L, Lederer C, et al. What is the "normal" fetal heart rate? PeerJ. 2013;1:e82.

3. Alfirevic Z, Devane D, Gyte GMI, Cuthbert A. Continuous cardiotocography (CTG) as a form of electronic fetal monitoring (EFM) for fetal assessment during labour. Cochrane Database Syst Rev. 2017;2017:Cd006066.

4. Di Tommaso M, Seravalli V, Cordisco A, Consorti G, Mecacci F, Rizzello F. Comparison of five classification systems for interpreting electronic fetal monitoring in predicting neonatal status at birth. $J$ Matern Fetal Neonatal Med. 2013;26:487-490.

5. Geary M. FIGO news. Int J Gynecol Obstet. 1987;25:159-167.

6. 2019 Surveillance of Intrapartum Care for Healthy Women and Babies (NICE Guideline CG190). National Institute for Health and Care Excellence (UK). Copyright (C) NICE 2019; 2019.

7. Gynaecologists RAaNZCoOa. Intrapartum fetal surveillance clinical guideline-fourth edition [pdf]. November 15, 2019 [cited January 18, 2021]; fourth:[Clinical Guideline]. https://ranzcog.edu. au/RANZCOG_SITE/media/RANZCOG-MEDIA/Women\%27s\%20 Health/Statement\%20and\%20guidelines/Clinical-Obstetrics/IFSGuideline-4thEdition-2019.pdf?ext=.pdf

8. Dore S, Ehman WN. No. 396-fetal health surveillance: intrapartum consensus guideline. J Obstet Gynaecol Can. 2020;42:316-48.e9.

9. ACOG practice bulletin no. 106: intrapartum fetal heart rate monitoring: nomenclature, interpretation, and general management principles. Obstet Gynecol. 2009;114:192-202.

10. Ayres-de-Campos D, Spong CY, Chandraharan E. FIGO consensus guidelines on intrapartum fetal monitoring: cardiotocography. Int J Gynaecol Obstet. 2015;131:13-24.

11. Swedish Society for Obstetricians and Gynecologists. Svenska riktlinjer för bedömning av INTRApartalt CTG [Swedish guidelines for assessment of INTRApartal CTG] [pdf]. March 6, 2019 [cited January 18, 2021]. https://lof.se/filer/INTRA-partalt-ctg_ tryck.pdf

12. Stephansson O, Petersson K, Björk C, Conner P, Wikström AK. The Swedish Pregnancy Register-for quality of care improvement and research. Acta Obstet Gynecol Scand. 2018;97:466-476.

13. Petersson K, Persson $M$, Lindkvist $M$, et al. Internal validity of the Swedish Maternal Health Care Register. BMC Health Serv Res. 2014;14:364.

14. Norman $\mathrm{M}$, Källén $\mathrm{K}$, Wahlström E, et al. The Swedish Neonatal Quality Register-contents, completeness and validity. Acta Paediatr. 2019;108:1411-1418.

15. Levene MI, Sands C, Grindulis H, Moore JR. Comparison of two methods of predicting outcome in perinatal asphyxia. Lancet. 1986;1:67-69.
16. Sarnat HB, Sarnat MS. Neonatal encephalopathy following fetal distress. A clinical and electroencephalographic study. Arch Neurol. 1976;33:696-705.

17. Jacobs SE, Berg M, Hunt R, Tarnow-Mordi WO, Inder TE, Davis PG. Cooling for newborns with hypoxic ischaemic encephalopathy. Cochrane Database Syst Rev. 2013;2013:Cd003311.

18. Källén BK, K. The Swedish Medical Birth Register-a summary of content and quality. Research report. socialstyrelsen.se; 2003. Report No.: 2003-112-3.

19. Cnattingius S, Ericson A, Gunnarskog J, Källén B. A quality study of a medical birth registry. Scand J Soc Med. 1990;18:143-148.

20. Coletta J, Murphy E, Rubeo Z, Gyamfi-Bannerman C. The 5-tier system of assessing fetal heart rate tracings is superior to the 3-tier system in identifying fetal acidemia. Am J Obstet Gynecol. 2012;206(226):e1-5.

21. Bhatia M, Mahtani KR, Nunan D, Reddy A. A cross-sectional comparison of three guidelines for intrapartum cardiotocography. Int $J$ Gynaecol Obstet. 2017;138:89-93.

22. Santo S, Ayres-de-Campos D, Costa-Santos C, Schnettler W, Ugwumadu A, Da Graça LM. Agreement and accuracy using the FIGO, ACOG and NICE cardiotocography interpretation guidelines. Acta Obstet Gynecol Scand. 2017;96:166-175.

23. Martí Gamboa S, Giménez OR, Mancho JP, Moros ML, Sada JR, Mateo SC. Diagnostic accuracy of the FIGO and the 5-tier fetal heart rate classification systems in the detection of neonatal acidemia. Am J Perinatol. 2017;34:508-514.

24. Kundu S, Kuehnle E, Schippert C, von Ehr J, Hillemanns P, Staboulidou I. Estimation of neonatal outcome artery $\mathrm{pH}$ value according to CTG interpretation of the last 60 min before delivery: a retrospective study. Can the outcome $\mathrm{pH}$ value be predicted? Arch Gynecol Obstet. 2017;296:897-905.

25. Olofsson P, Norén H, Carlsson A, Rosén KG. Identifying newborns with umbilical cord blood metabolic acidosis by intrapartum cardiotography combined with fetal ECG ST analysis (STAN): comparison of the new and old FIGO systems to classify cardiotocograms. J Matern Fetal Neonatal Med. 2020;33:404-409.

26. Ekengård F, Cardell M, Herbst A. Impaired validity of the new FIGO and Swedish CTG classification templates to identify fetal acidosis in the first stage of labor. J Matern Fetal Neonatal Med. 2021;6:1-8. 10.1080/14767058.2020.1869931. Epub ahead of print.

27. Ekengård $\mathrm{F}$, Cardell $\mathrm{M}$, Herbst $\mathrm{A}$. Low sensitivity of the new FIGO classification system for electronic fetal monitoring to identify fetal acidosis in the second stage of labor. Eur J Obstet Gynecol Reprod Biol X. 2021;9:100120.

\section{SUPPORTING INFORMATION}

Additional supporting information may be found in the online version of the article at the publisher's website.

How to cite this article: Jonsson M, Söderling J, Ladfors L, et al. Implementation of a revised classification for intrapartum fetal heart rate monitoring and association to birth outcome: A national cohort study. Acta Obstet Gynecol Scand. 2022;101:183-192. doi:10.1111/aogs.14296 